\title{
Increased total polyphenol content, antioxidant capacity and $\gamma$-aminobutyric acid content of roasted germinated native Thai black rice and its microstructure
}

\author{
Naruemon MONGKONTANAWAT ${ }^{1 *}$ (D), Yuto UEDA², Shin YASUDA ${ }^{2}$
}

\begin{abstract}
The effects of roasting on the colour parameters, anthocyanin content, total polyphenol content, antioxidant activity, $\gamma$-aminobutyric acid (GABA) content, and the microstructure of germinated Thai black rice (GTBR: non-waxy) and germinated Thai black sticky rice (GTBSR: waxy) were appraised. The results revealed that both types of roasted germinated Thai black rice showed an increase in all lightness $\left(\mathrm{L}^{*}\right)$, redness $\left(\mathrm{a}^{*}\right)$ and yellowness $\left(\mathrm{b}^{*}\right)$. For the chemical properties, only the concentration of anthocyanin slightly decreased, whereas the total polyphenol content, $\mathrm{ABTS}^{+}$radical scavenging activity, and GABA content markedly increased after roasting. Moreover, images of a scanning electron microscope (SEM) displayed that both germinated black rice grains became more compact and had a tight shape in the surface structure. Additionally, small pores were found in the GTBR and large pores were present in the GTBSR rice kernel when compared with the unroasted black rice in the internal structure. Together, the roasting process was capable of enhancing the GABA and phenolic contents, and antioxidative capacity in both the GTBR and GTBSR.
\end{abstract}

Keywords: roasting; $\gamma$-aminobutyric acid (GABA); microstructure; black rice.

Practical Application: Improve the bioactive compounds of Thai black rice grain kernel after germination.

\section{Introduction}

Nowadays, black rice has received attention due to its high nutritive value and sensory characteristics. It contains various nutritional and bioactive components composed of essential amino acids, functional lipid, dietary fibre, vitamins, minerals, anthocyanins, phenolic compounds, $\gamma$-oryzanol, tocopherols, tocotrienols,phytosterols and phytic acid (Ito \& Lacerda, 2019; Kong \& Lee, 2010). Additionally, black rice has higher protein, fat, ash, crude fibre content, phytate, polyphenol contents, and antioxidant activity than normal white rice, while low in sugar, fat, and free of cholesterol (Ito \& Lacerda, 2019; Liu et al., 2020; Pengkumsri et al., 2015).

The main compounds of secondary metabolites of black rice were reported in rice grown in the Camargue region of France by Pereira-Caro et al. (2013). They reported that anthocyanin $(3.50 \mathrm{mg} / \mathrm{g}$ ) was the main compound with cyaniding-3-O-glucoside and peonidin 3-O-glucoside predominating, followed by flavones, flavonols $(0.5 \mathrm{mg} / \mathrm{g})$ and flavan-3-ols $(0.3 \mathrm{mg} / \mathrm{g})$, which comprised monomeric and oligomeric constituents. Furthermore, quantities of $\gamma$-oryzanols, including 24-methylenecycloartenol, campesterol, cycloartenol,and $\beta$-sitosterol ferulates, were detected along with lower levels of carotenoids $(6.5 \mu \mathrm{g} / \mathrm{g})$. In addition, in order to increase health benefits, germinated rice is a good staple cereal food source of natural $\gamma$-aminobutyric acid (GABA).

The health benefits of this substance for humans has been widely recognised around the world. GABA is a neurotransmitter in the brain and the spinal cord of mammals. This substance can lower hypertension and promote sleepiness (Okada et al., 2000). Additionally, the germination of black rice frees bound minerals making them more absorbable by the body and generating a tastier activity (Karahara, 2004). From this nutritional point of black rice, studies have been conducted on the optimisation of the dry roasting of flaked rice in common salt and on associated changes in the chemical, nutritional, optical, physical, rheological, and textural attributes. The results displayed that the roasting temperature and time had a significant influence $(\mathrm{p} \leq 0.05)$ on the parameters, i.e., whiteness index, yellowness index, hardness, expansion ratio, hydroxyl methyl furfural, and overall acceptability (Kumar \& Prasad, 2017). Moreover, Lee et al. (2003) reported that the roasting led to a decrease in the $\mathrm{L}^{*}$ value and an increase in the $\mathrm{a}^{*}$ and $\mathrm{b}^{*}$ values from both roasted rice flour and Tarak-juk.

Chatthongpisut et al. (2015) reported that Thai purple rice cooked under sterilisation could be a potential source of protocatechuic acid (PCA) exerting high antiproliferative activity. Tang et al. (2016) studied the outcome of phenolic chemical compositions and antioxidant activities in waxy and non-waxy black rice during home cooking. The results exhibited that greater phenolics and antioxidant capacities were detected in non-waxy rice rather than the waxy kind. Furthermore, all processed black rice showed a significantly lower total phenolic content, total flavonoid content, condensed tannin content,monomeric anthocyanin 
content, cyaniding-3-glucoside and peonidin-3-glucoside than the control $(\mathrm{p}<0.05)$. They suggested that black rice porridge could gain more health promoting effects and could maintain the bioavailability of the active components.

Shi et al. (2018) concluded that the microstructural change of brown rice during roasting affected the volatilisation of the aroma compounds. Moreover, the roasting process made an increase in the content of the heterocycle compounds, while a decrease in types of hydrocarbons and benzene derivatives. Furan and pyrazines made a great contribution to the aroma quality Purfural,5-methylfurfural,2,5-dimethylpyrazine,2-methylpyraz ine,2-ethyl-6-methylpyrazine,and 2-ethyl-3,5-dimethylpyrazine were the main flavour compounds in the roasted brown rice. Wu et al. (2013) reported that significant cyanidin-3-glucoside and peonidin-3-glucosidetotal content in black rice grains decreased during soaking, steaming, and roasting $(\mathrm{p}<0.05)$. In contrast, only steaming and roasting caused a significant decrease in the content of total starch and crude fat.

In general, powerful processing technology, which increases the amount of real aroma compounds is roasting. Black rice could form a unique flavor and increase the favourite degree of consumers (Shi et al., 2018). An et al. (2016) evaluated the in vitro potential of phenolic phytochemicals from black rice in the starch digestibility and rheological behaviour. They found that the phenolic compounds had more critical factors compared to the dietary fibre for retarding in vitro starch-based food prepared with black rice.

In the authors'previous research, native black rice (KhaoHawm Mae Paya Tong Dam) was studied for determining the germination percentage (\%) and length of the roots after different storage times of one, two, three, four, five and six months, respectively. The authors found a decrease in the length of the roots and the germination percentage at the end of six months. Then, some nutritional values of germinated native black rice were studied. The results indicated that $\gamma$-aminobutyric acid had slightly increased when the rice had been stored for a longer period of time, whereas vitamin $\mathrm{B} 1$, the protein content, $\mathrm{DPPH}$ scavenging activity, and phenolic compounds were decreased when the shelf life was longer. However, the moisture content still increased significantly $(\mathrm{p} \leq 0.05)$ after six months of storage (Mongkontanawat\&Phuangborisut, 2017).

However, the effects of roasting on the physico-chemical properties and microstructure of the germinated native Thai black rice has never been fully elucidated. Therefore, the current study focused on the effects of roasting on the colour parameters, anthocyaninand total polyphenol contents, the antioxidant activity, $\gamma$-aminobutyric acid content, and the grain microstructure oftwo cultivars of germinated Thai black rice (GTBR:non-waxy) and germinated Thai black sticky rice (GTBSR: waxy).

\section{Materials and methods}

\subsection{Materials}

The rice species used in this research was Oryza sativa comprising the non-waxy and waxy variants. Those cultivars of Thai black rice (KhaoHawm Mae Paya Tong Dam(TBR)) and
Thai black sticky rice (KhaoHawmChan Ocha(TBSR)) produced in 2018 were purchased from local farmers in Khao Khitchakut district, Chanthaburi province, Thailand. Dimethyl sulfoxide (DMSO), ABTS, DPPH, Folin-Ciocalteu's phenol reagent, Trifluoroacetic acid, and potassium peroxodisulfate were purchased from Nacalai Tesque, Inc. (Kyoto, Japan). $\gamma$-Aminobutyric acid (GABA), sodium hypochlorite $(\mathrm{NaClO})$, and phenol reagent were purchased from CTI \& Science Co,. Ltd. (Bangkok, Thailand). All other chemicals were of the highest grade and were commercially available.

\subsection{Methods}

\section{Preparation of the germinated black rice and extracts}

Germinated black rice was first prepared according to the modified methods by Panyanak et al. (2010) with some minor modifications. Both of the black rice samples were selected and soaked in water at the ratio of rice and water $1: 10$ at $40{ }^{\circ} \mathrm{C}$ for six hours in a tray. Secondly, the water was drained. The black rice samples were germinated for 48 hours at room temperature $\left(25^{\circ} \mathrm{C}\right)$. Then, the germination was stopped by drying using a hot air oven, at $55^{\circ} \mathrm{C}$ for 4.5 hours. Finally, the obtained germinated native black rice was stored at room temperature $\left(25^{\circ} \mathrm{C}\right)$ before use. Then, the two cultivars of germinated Thai black rice were roasted by using a home coffee bean roaster machine (Nesco Home Coffee Bean Roaster, USA) at approximately $200{ }^{\circ} \mathrm{C}$ for 20 minutes. The samples were moved to room temperature $\left(\sim 25^{\circ} \mathrm{C}\right)$, then the roasted material was obtained. Four extracts from the germinated native black rice were prepared by water extraction as described previously (Oliveira et al., 2009) with some modifications. Briefly, approximately $1 \mathrm{~g}$ of crashed black rice was soaked in $50 \mathrm{~mL}$ of Milli-Q water in a conical beaker at $90-100{ }^{\circ} \mathrm{C}$ for 45 minutes. The black rice mixture was then centrifuged and filtrated. The hot water extract was obtained from the filtrated rice, and then determined the anthocyanin content, total polyphenol, and antioxidant activity.

\section{Determination of the colour parameters}

For the evaluation of the colour parameters, black rice grain was measured by using a colour metre (Nippon Denshoku, ZE-2000, Japan). The equipment was calibrated with a standard plate. The colour measurement was expressed in $L^{*}$ indicating the lightness on a $0-100$ scale from black to white and $a^{*}(+,-)$ indicated the redness or greenness, whereas $b^{*}(+,-)$ indicated yellowness and blueness.

\section{Determination of the anthocyanin content}

The amount of the anthocyanin content was investigated by an established procedure from Oki et al. (2002). Briefly, the mixture containing $5 \mu \mathrm{L}$ of extracted black rice samples and $245 \mu \mathrm{L}$ of $1 \%$ of trifluoroacetic acid in Milli-Q water was mixed for 30 minutes at room temperature. The absorbance of the resulting solution was measured at $530 \mathrm{~nm}$ by using a plate reader. Cyaniding-3-O-glucoside was used as the standard. 


\section{Determination of the total polyphenol content}

The level of the total polyphenol was evaluated by an established procedure (Singleton \& Rossi, 1965). Briefly, the reaction containing $25 \mu \mathrm{L}$ of black rice samples and 10- times diluted $125 \mu \mathrm{L}$ of Folin-Ciocalteu's phenol reagent solution was mixed with $10 \%$ of sodium carbonate solution $(125 \mu \mathrm{L})$ for 10 minutes at room temperature. The mixture was shaken for 10 minutes in a dark condition and then stood for five minutes at room temperature.The absorbance of the resulting solution was measured at $600 \mathrm{~nm}$ by using a plate reader.

\section{$A B T S^{+}$radical scavenging assay}

The $\mathrm{ABTS}^{+}$radical scavenging activity was performed based on the following method (Thaipong et al., 2006). Briefly, the ABTS-mixture solution was first prepared by mixing $7.4 \mathrm{mM}$ of the ABTS and $2.6 \mathrm{mM}$ of the potassium peroxodisulfate solutions in an equal amount for a 15-hour rotation in the dark at room temperature. Next, the ABTS working solution was prepared after the dilution of the ABTS mixture solution $(150 \mu \mathrm{L})$ in methanol $(2.9 \mathrm{~mL})$ before being evaluated. The reaction was started by adding $190 \mu \mathrm{L}$ of the ABTS working solution into $10 \mu \mathrm{L}$ of various concentrations of extracted black rice samples. Then, the reaction was allowed at room temperature for two hours in the dark condition. The absorbance of the resulting solution was measured at $734 \mathrm{~nm}$ by using a plate reader. Trolox was used as the standard sample. The radical scavenging activity was expressed in terms of the micromole TE per gramme of the sample (dry weight).

\section{Determination of the $\gamma$-aminobutyric acid(GABA) content}

The amount of the GABA content was determined by the modified method of Sansenya et al. (2017). Briefly, black rice sample ( $2 \mathrm{~g}$ ) was weighed into a $15-\mathrm{mL}$ test tube and dissolved with deionised water $(5 \mathrm{~mL})$, and then extracted for one hour, followed by centrifugation at $10,000 \mathrm{rpm}$ for 15 minutes. The supernatant was filtered by using a syringe filter $(0.45 \mu \mathrm{m})$, and then $0.5 \mathrm{~mL}$ of the filtered sample was mixed with $0.2 \mathrm{~mL}$ of $0.2 \mathrm{M}$ borate buffer $\mathrm{pH} 9.0,1 \mathrm{~mL}$ of $6 \% \mathrm{w} / \mathrm{v}$ phenol reagent and $0.4 \mathrm{~mL}$ of $9 \% \mathrm{w} / \mathrm{v} \mathrm{NaClO}$. The reaction mixture was boiled for 10 minutes, and then cooled in a cooling bath for 20 minutes or until a blue colour appeared. The absorbance of the resulting solution was measured at $645 \mathrm{~nm}$ by using a spectrophotometer. The GABA content of the test sample was quantified by comparing the value of the absorption with the content curve of the standard GABA; $y=400.4 x+0.032\left(R^{2}=0.983\right)$.

\section{Determination of the microstructure}

The four germinated black rice samples were prepared by fixing on the stab and then were photographed with a scanning electron microscope (SEM) (JEOL, model JSM-MEDEL jsm-5410LV, Japan) at a magnification of $16 \mathrm{x}$ and $1,000 \mathrm{x}$, respectively to capture the images of the grain's appearance, surface structure and internal structure.

\section{Experimental design and statistical analysis}

For the analyses of the physico-chemical properties, a completely randomised design with three replications was used. The analyses of the above-mentioned properties were conducted and expressed as the mean \pm standard deviation (S.D.). The data were subjected to the analysis of variance (ANOVA) $(p \leq 0.05)$. The mean with significant differences was separated by the Wilcoxon Signed Ranks Test, and the difference was considered statistically significant when the $P$ value was less than 0.05 .

\section{Results and discussion}

The aim of this study was to comparatively evaluate some of the physico-chemical properties and microstructure of two cultivars of germinated Thai black rice (non-waxy: GTBR) and germinated Thai black sticky rice (waxy rice:GTBSR) grown in Thailand.These rice samples were germinated at room temperature for 48 hours and then roasted using a roaster machine. The roasted black rice samples were assessed for determining the changes in the anthocyanin and total polyphenol contents, antioxidant activity, $\gamma$-aminobutyric acid content, and microstructure of the roasted germinated black rice grain.

For the colour parameters of the roasted germinated black rice, Table 1 shows the lightness $\left(\mathrm{L}^{*}\right)$, redness $\left(\mathrm{a}^{*}\right)$, and yellowness $\left(b^{*}\right)$ of both the GTBR and GTBSR.After roasting,these values were significantly increased ( $\mathrm{p} \leq 0.05$ ). This was possibly due to the occurrence of the Maillard reaction.

For the anthocyanin content, total phenol content and radical scavenging activity of the non-roasted and roasted germinated Thai black rice,as shown in Figure 1, the anthocyanin content of the GTBSR was higher than that of the GTBR. This finally resulted in a lower decrease in the content of the anthocyanin in the GTBR with an absolute difference in the raw and roasted rice content ranging from $0.11 \pm 0.01$ to $0.09 \pm 0.06 \mathrm{mg} / \mathrm{g}$ GTBR dry weight and from $0.31 \pm 0.08$ to $0.23 \pm 0.12 \mathrm{mg} / \mathrm{g}$ GTBSR dry weight. This result indicated that, during roasting, there was a major loss of the anthocyanins. This outcome was consistent with Surh \& Koh (2014), who found that roasting resulted in the

Table 1. Changes in the colour parameters $\left(\mathrm{L}^{*} ; \mathrm{a}^{*} ; \mathrm{b}^{*}\right)$ ofthe GTBR and GTBSR before and after roasting.

\begin{tabular}{|c|c|c|c|c|c|c|}
\hline \multirow{3}{*}{$\begin{array}{l}\text { Germinated Thai } \\
\text { black rice cultivars }\end{array}$} & \multicolumn{6}{|c|}{ Colour parameters } \\
\hline & \multicolumn{2}{|c|}{$\mathrm{L}^{*}$} & \multicolumn{2}{|c|}{$\mathrm{a}^{*}$} & \multicolumn{2}{|c|}{$b^{*}$} \\
\hline & Non-roasted seeds & Roasted seeds & $\begin{array}{c}\text { Non-roasted } \\
\text { seeds }\end{array}$ & Roasted seeds & Non-roasted seeds & Roasted seeds \\
\hline GTBR & $24.10 \pm 0.14^{b}$ & $24.70 \pm 0.14^{a}$ & $1.34 \pm 0.05^{b}$ & $3.10 \pm 0.10^{a}$ & $3.43 \pm 0.12^{b}$ & $6.31 \pm 0.06^{\mathrm{a}}$ \\
\hline GTBSR & $24.16 \pm 0.11^{b}$ & $25.46 \pm 0.06^{\mathrm{a}}$ & $1.65 \pm 0.14^{b}$ & $2.57 \pm 0.06^{\mathrm{a}}$ & $4.43 \pm 0.10^{b}$ & $7.72 \pm 0.02^{\mathrm{a}}$ \\
\hline
\end{tabular}

The data represent the mean \pm S.D. from the three experiments. Germinated Thai black rice $=$ GTBR; germinated Thai black sticky rice $=$ GTBSR 
greatest reduction in the black rice anthocyanin content (94\%). Moreover, a significant decrease in the total contents of cyanidin3 -glucoside and peonidin-3-glucoside $(\mathrm{p}<0.05)$ was reported in the black rice grains during roasting, soaking, and steaming (Wu et al., 2013). In addition, the total anthocyanin and cyanidin3-glucoside was decreased by thermal cooking (Bhawamai et al., 2016), and cyanidin-3-glucoside was predominantly found to have protocatechuic acid during roasting (Hiemori et al., 2009).

As shown in Figures 2 and 3, the total polyphenol content and antioxidant activity of the GTBR(non-waxy black rice) was slightly higher than those of the GTBSR(waxy black rice). This result corresponded with Tang et al. (2016), who also exhibited that greater phenolic and antioxidant capacities were detected in non-waxy black rice rather than the waxy kind. Interestingly, the total polyphenol content in the roasted GTBR and GTBSR significantly increased from 7.02 $\pm 0.48,5.12 \pm 0.35$ to $8.47 \pm 0.28,6.80 \pm 0.46 \mathrm{mg} \mathrm{CAE} / \mathrm{g}$ dry weight, respectively $(\mathrm{p} \leq 0.05)$ (Figure 2). Cyaniding-3-glucoside could be degraded to phloroglucinaldehyde and protocatechuic acid in the thermal process (Hiemori et al., 2009; Ito \& Lacerda, 2019). This indicated that the decrease of the anthocyanin content observed here was plausibly due to its degradation upon roasting. In contrast, the total polyphenol content was increased in line with the increase of the antioxidant activity (Figures 2 and 3). Together, roasting degraded anthocyanins had a concomitant increase in the phenolics with the degradation of the anthocyanins. This outcome corresponded with Ryu \& Koh (2016) who reported that roasting could cause a significant increase in the total amount of free phenolic acids(protocatechuic acid) by 4-10 times in the two cultivars of Korean black rice.

As a parameter of the antioxidant activity, the $\mathrm{ABTS}^{+}$ radical scavenging activity in the roasted GTBR and GTBSR significantly increased from $206.63 \pm 10.87$ and $174.62 \pm 16.05$ to $282.10 \pm 51.27$ and $258.57 \pm 31.64 \mathrm{mgTE} / \mathrm{g}$ dry weight, respectively $(\mathrm{p}<0.05)$ (Figure 3). This finding was in agreement with the results of $\mathrm{Hu}$ et al. (2017) who reported that the total phenolic content and antioxidant activity of germinated red rice parboiled for five and 15 minutes was higher than that of germinated red rice. Phenolic compounds are the major antioxidant and radical scavenging ingredients in rice (Watanabe et al., 2016). The level of the total polyphenol content was increased after roasting in this current research; therefore, the antioxidant activity was also increased, too.

For the $\gamma$-aminobutyric content of non-roasted and roasted germinated Thai Black rice, interestingly, the $\gamma$-aminobutyric acid of the GTBR and GTBSR after roasting significantly increased both cultivars approximately four times and nine times for the GTBR and GTBSR, respectively ( $\mathrm{p} \leq 0.05)$ (Figure 4). This result corresponded with Kwak (2010), who found that 10 minutes of roasting at $170^{\circ} \mathrm{C}$ contained the highest GABA in brown coloured rice tea.

For the microstructure of non-roasted and roasted germinated Thai black rice,the SEM images of the appearance, surface, and internal aspects of the GTBR and GTBSR after roasting are presented in Figure5. In the surface structure, both germinated black rice grains became more compact and had a tight shape. Compared with the unroasted black rice, the SEM revealed a

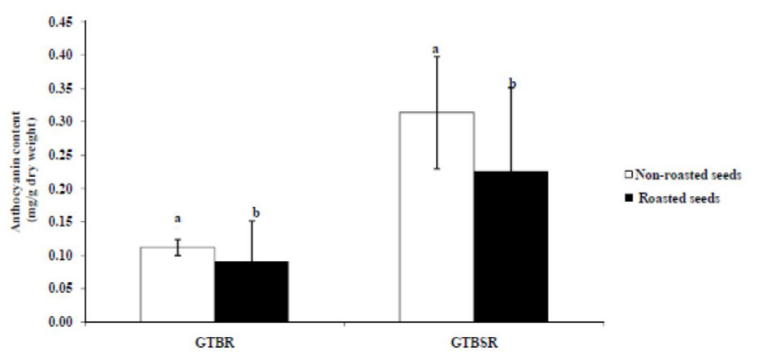

Figure 1. Changes in the anthocyanin content of hot water extracts of GTBR and GTBSR after roasting. The data represent the mean \pm S.D. from the three experiments. Germinated Thai black rice = GTBR; germinated Thai black sticky rice $=$ GTBSR.

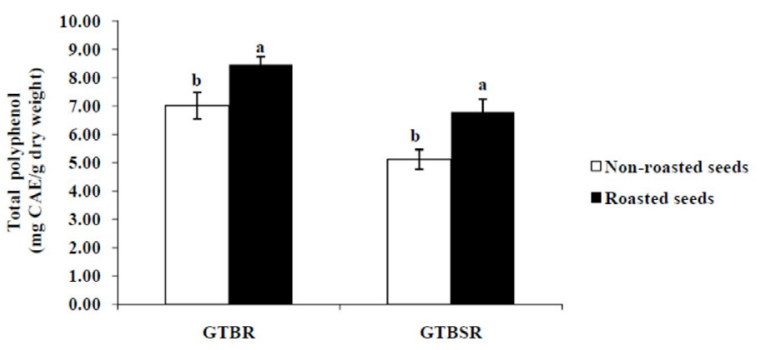

Figure 2. Changes in the total polyphenol content of the hot water extracts from the GTBR and GTBSR after roasting. The data represent the mean \pm S.D. from the three experiments. Germinated Thai black rice $=$ GTBR; germinated Thai black sticky rice $=$ GTBSR .

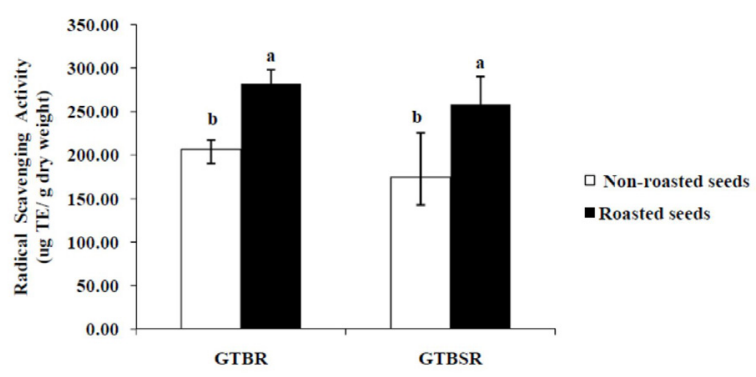

Figure 3. Changes in the antioxidative activities $\left(\mathrm{ABTS}^{+}\right.$radical) of the GTBR and GTBSR after roasting. The data represent the mean \pm S.D. from the three experiments. Trolox was used as the standard sample. Germinated Thai black rice = GTBR; germinated Thai black sticky rice $=$ GTBSR .

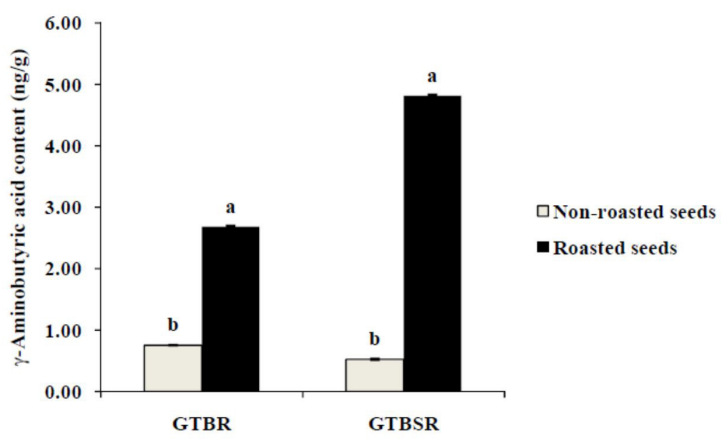

Figure 4. Changes in the $\gamma$-aminobutyric acid content of the GTBR and GTBSR after roasting. The data represent the mean \pm S.D. from the three experiments. Germinated Thai black rice = GTBR; germinated Thai black sticky rice $=$ GTBSR . 


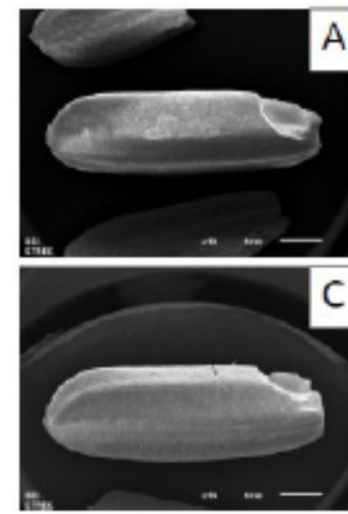

Grain appearance

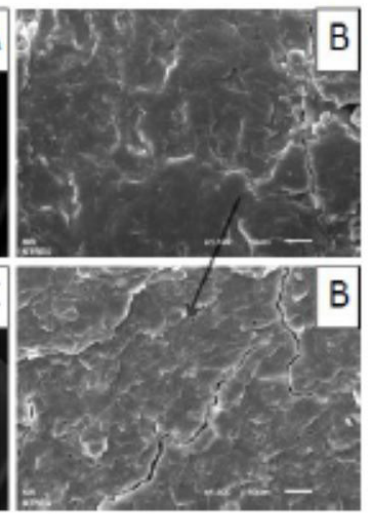

Internal structure

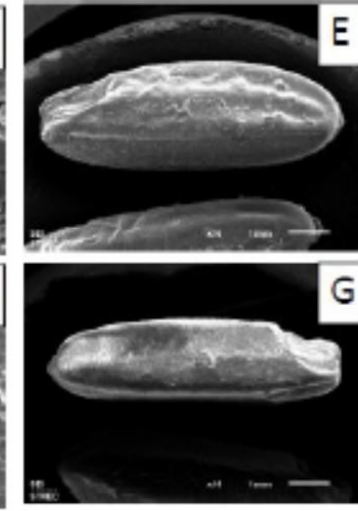

Grain appearance

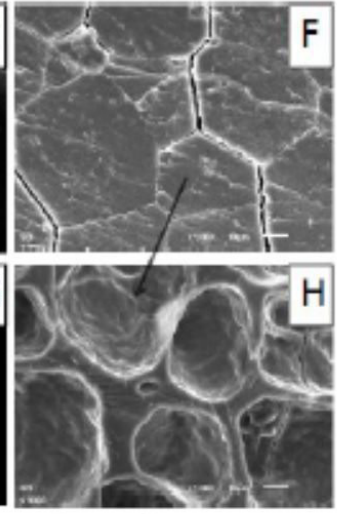

Internal structure
Non-roasted seeds

Roasted seeds GTBR

\section{GTBSR}

Figure 5. Scanning electron microscope photos of the GTBR and GTBSR before (A and E: grain appearance,16x; B: surface structure; B and F: internal structure, 1000x) and after roasting (C andG: grain appearance,16x; B and H, internal structure, 1000x). Germinated Thai black rice = GTBR; germinated Thai black sticky rice $=$ GTBSR.The arrows indicate the small and larger poresof the roasted GTBR and GTBSR, respectively.

highly small porein the GTBR, and an evaporated and large amount of precursor compounds were heated for the chemical reactions during the larger poresin the GTBSR rice kernel.This could be considered because the moisture in black rice was part of the roasting process. The crude fibre could be broken and the internal microstructure of the black rice was changed, then the volatile aroma compounds might be evaporated. Thus, in roasting black rice, the pores would occur (Shi et al., 2018). It was noted that roasting brown rice not only contributed to a complete alteration of the microstructure, but also of the compounds of the aroma. Moreover, under the high temperature, the carbonyl compounds could react with the amino acids, thereby producing brownish black substances with a special flavour. As such, it was considered that this reaction was the main mechanism for browning in the case of brown rice. The change of the starch granules structure and the disappearance of the protein film in the roasted brown rice was also reported(ibid).

\section{Conclusion}

The overall results indicated the effects of roasting on the increased lightness $\left(L^{*}\right)$, redness $\left(a^{*}\right)$, and yellowness $\left(b^{*}\right)$ of both germinated Thai non-waxy and waxy black rice. It was emphasised that the roasting process decreased the anthocyanins, while it increased the total polyphenol content, $\mathrm{ABTS}^{+}$radical scavenging activity, and GABA content of both germinated black rice cultivars. These findings may provide useful information to understand the effect of roasting on the changes of the physico-chemical properties and the microstructure of Thai black rice grain kernel following germination. More research is warranted to establish the germinated Thai black rice grain with roasting to be a better source for health-promoting foodstuffs.

\section{Acknowledgements}

The authors are very grateful to the Matsumae International Foundation (MIF), Japan for their financial support and the colleagues in Prof. Dr. Shin Yasuda's laboratory for their help in this research.

\section{References}

An, J. S., Bae, I. Y., Han, S. I., Lee, S. J., \& Lee, H. G. (2016). In vitro potential of phenolicphytochemicals from black rice on starch digestibility and rheological behaviors. Journal of Cereal Science, 70, 214-220. http://dx.doi.org/10.1016/j.jcs.2016.06.010.

Bhawamai, S., Lin, S. H., Hou, Y. Y., \& Chen, Y. H. (2016). Thermal cooking changes the profile of phenolic compound, but does not attenuate the anti-inflammatory activities of black rice. Food \& Nutrition Research, 60(1), 32941. http://dx.doi.org/10.3402/fnr. v60.32941. PMid:27652685.

Chatthongpisut, R., Schwartz, S. J., \& Yongsawatdigul, J. (2015). Antioxidant activity and antiproliferative activity of Thai purple rice cooked by various methods on human colon cancer cells. Food Chemistry, 188, 99-105. http://dx.doi.org/10.1016/j.foodchem.2015.04.074. PMid:26041170.

Hiemori, M., Koh, E., \& Mitchell, A. E. (2009). Influence of cooking on anthocyanins in black rice (Oryza sativa L. japonica var.SBR.). Journal of Agricultural and Food Chemistry, 57(5), 1908-1914. http:// dx.doi.org/10.1021/jf803153z. PMid:19256557.

Hu, Z., Tang, X., Liu, J., Zhu, Z., \& Shao, Y. (2017). Effect of parboiling on phytochemical content, antioxidant activity and physicochemical properties of germinated red rice. Food Chemistry, 214, 285-292. http://dx.doi.org/10.1016/j.foodchem.2016.07.097. PMid:27507477.

Ito, V. C., \& Lacerda, L. G. (2019). Black rice (Oryza sativa L.): a review of its historical aspects, chemical composition, nutritional and functional properties, and application and processing technologies. Food Chemistry, 301, 125304. http://dx.doi.org/10.1016/j. foodchem.2019.125304. PMid:31394335.

Karahara, H. (2004). Germinated brown rice (pp. 1-32). Japan: Department of Sciences of Functional Food, Shinshu University.

Kong, S., \& Lee, J. (2010). Antioxidants in milling fractions of black rice cultivars. Food Chemistry, 120(1), 278-281. http://dx.doi. org/10.1016/j.foodchem.2009.09.089.

Kumar, S., \& Prasad, K. (2017). Optimization of flaked rice dry roasting in common salt and studies on associated changes in chemical, nutritional, optical, physical, rheological and textural attributes. Asian Journal of Chemistry, 29(6), 1380-1392. http://dx.doi.org/10.14233/ ajchem.2017.20563. 
Kwak, E. J. (2010). Development of brown colored rice tea with high GABA content. Journal of the Korean Society of Food Science and Nutrition, 39(8), 1201-1205. http://dx.doi.org/10.3746/jkfn.2010.39.8.1201.

Lee, G. C., Kim, S. J., \& Koh, B. K. (2003). Effect of roasting condition on the physicpchemical properties of rice flour and quality characteristics of Tarakjuk. Korean Journal of Food Science Technology, 35, 905-913.

Liu, P., Li, Y., Gao, L., Zhou, X., Ma, P., \& Wang, Q. (2020). Effect of different carbohydrates on the functional properties of black, rice glutelin(BRG) modified by the maillard reaction. Journal of Cereal Science, 93, 1-7. http://dx.doi.org/10.1016/j.jcs.2020.102979.

Mongkontanawat, N., \& Phuangborisut, S. (2017). Effect of shelf life on germination percentage and some nutritional value of germinated native black rice. In Proceedings of The 5th International Conference on Chemical, Agricultural, Biological and Environmental Sciences (CAFES-17) (pp. 19-23). USA: Dignified Researchers in Agricultural, Biological and Life Sciences.

Okada, T., Sugishita, T., Murakami, T., Murai, H., Saikusa, T., Horino, T., Onoda, A., Kajimoto, O., Takahashi, R., \& Takahashi, T. (2000). Effect of the defatted rice germ enrich with GABA for sleepless, depression, autonomic disorder by oral administration. Nippon Shokuhin Kagaku Kogaku Kaishi, 47(8), 596-603. http://dx.doi. org/10.3136/nskkk.47.596.

Oki, T., Masuda, M., Kobayashi, M., Nishiba, Y., Furuta, S., Suda, I., \& Sato, I. (2002). Polymeric procyanidins as radical-scavenging components in red-hulled rice. Journal of Agricultural and Food Chemistry, 50(26), 7524-7529. http://dx.doi.org/10.1021/jf025841z. PMid:12475265.

Oliveira, I., Coelho, V., Baltasar, R., Pereira, J. A., \& Baptista, P. (2009). Scavenging capacity of strawberry tree (Arbutus nnedo L.) leaves on free radicals. Food and Chemical Toxicology, 47(7), 1507-1511. http://dx.doi.org/10.1016/j.fct.2009.03.042. PMid:19351553.

Panyanak, S., Suwanketnikom, S., Tonhang, S., \& Siripoonwiwat, W. (2010). Correlations between seed characteristics, seed germination and $\gamma$-aminobutyric acid (GABA) content of 14 rice cultivars. Thai Journal of Botany, 2, 97-113.

Pengkumsri, N., Chaiyasut, C., Saenjum, C., Sirilun, S., Peerajan, S., Suwannalert, P., Sirisattha, S., \& Sivamaruthi, B. S. (2015). Phytochemical and antioxidative properties of black rice, brown and red rice varieties of northern Thailand. Food Science and Technology (Campinas), 35(2), 331-338. http://dx.doi.org/10.1590/1678-457X.6573.
Pereira-Caro, G., Cros, G., Yokota, T., \& Crozier, A. (2013). Phytochemical profiles of black, red, brown, and white rice from the Camargue region of France. Journal of Agricultural and Food Chemistry, 61(33), 7976-7986. http://dx.doi.org/10.1021/jf401937b. PMid:23889299.

Ryu, C., \& Koh, E. (2016). Influence of cooking methods on free and bound phenolic acids in Korean black rice. Journal of Food Processing and Preservation, 41, 1-8.

Sansenya, S., Hua, Y., Chumanee, S., Phasai, K., \& Sricheewin, C. (2017). Effect of gamma irradiation on 2-acetyl-1-pyrroline content, GABA content and volatile compounds of germinated rice (Thai upland rice). Plants, 6(2), 1-12. http://dx.doi.org/10.3390/plants6020018. PMid:28489041.

Shi, Y., Wang, L., Fang, Y., Wang, H., Tao, H., Pei, F., Li, P., Xu, B., \& $\mathrm{Hu}$, Q. (2018). A comprehensive analysis of aroma compounds and microstructure changes in brown rice during roasting process. Lebensmittel-Wissenschaft + Technologie, 98, 613-621. http://dx.doi. org/10.1016/j.lwt.2018.09.018.

Singleton, V. L., \& Rossi, J. A. Jr. (1965). Colorimetry of total phenolics with phosphomolybdicphosphotungstic acid reagents. American Journal of Enology and Viticulture, 16, 144-158.

Surh, J.,\& Koh, E. (2014). Effect of four different cooking methods on anthocyanins, total phenolics and antioxidant activity of black rice. Journal of the Science of Food and Agriculture, 94, 3296-3304.

Tang, Y., Cai, W., \& Xu, B. (2016). From rice bag to table: Fate of phenolic chemical compositions and antioxidant activities in waxy and nonwaxy black rice during home cooking. Food Chemistry, 191, 81-90. http://dx.doi.org/10.1016/j.foodchem.2015.02.001. PMid:26258705.

Thaipong, K., Boonprakob, U., Crosby, K., Cisneros-Zevallos, L., \& Hawkins Byrne, D. (2006). Comparison of ABTS, DPPH, FRAP and ORAC assays for estimating antioxidant activity from guava fruit extracts. Journal of Food Composition and Analysis, 19(6-7), 669-675. http://dx.doi.org/10.1016/j.jfca.2006.01.003.

Watanabe, S., Hirakawa, A., Nishijima, C., Ohtsubo, K. I., Nakamura, K., Beppu, S., Tungtrakul, P., Quin, S. J., Tee, E. S., Tsuno, T., \& Ohigashi, H. (2016). Food as medicine: the new concept of "Medical Rice". Advances in Food Technology and Nutritional Sciences, 2(2), 38-50. http://dx.doi.org/10.17140/AFTNSOJ-2-129.

Wu, L., Zhai, M., Yao, Y., Dong, C., Shuang, S., \& Ren, G. (2013). Change in nutrition constituents, anthocyanins and volatile compounds during the processing of black rice tea. Food Science and Biotechnology, 22(4), 917-923. http://dx.doi.org/10.1007/s10068-013-0164-z. 